\title{
Cancer or COVID-19? A Review of Guidelines for Safe Cancer Care in the Wake of the Pandemic
}

\author{
Manit K. Gundavda ${ }^{1} \cdot$ Kaival K. Gundavda ${ }^{2}$
}

Accepted: 2 November 2020 / Published online: 21 November 2020

(C) Springer Nature Switzerland AG 2020

\begin{abstract}
In the wake of the COVID-19 pandemic, due to reasons beyond control, health care workers have struggled to deliver treatment for the patients with cancer. The concern for otherwise healthy patients with curable cancers that require timely intervention or therapy is the risk of contracting COVID-19 may outweigh the benefits of cancer treatment. Lack of international guidelines leaves health care providers with a case-to-case approach for delivering optimal cancer care in the wake of the pandemic. Transition to telemedicine has somewhat bridged the gap for in-office visits, but there is a continuing challenge of delays in cancer screening or significant decline of new diagnoses of cancers due to the pandemic. We aim to propose a balance in risk from treatment delay versus risks from COVID-19 with emphasis on treatment modality (surgery, radiation, and systemic therapy) as well as supportive care for cancer patients, and therefore have reviewed the publications and recommendations from international societies and study groups available as of October 2020.
\end{abstract}

Keywords Cancercare $\cdot$ COVID-19 pandemic $\cdot$ Disruption in oncology care $\cdot$ Resumption of elective surgeries $\cdot$ Supportive cancer care $\cdot$ Re-planning radiation therapy $\cdot$ Medical oncology treatments $\cdot$ Prevention of SARS-CoV-2 infection $\cdot$ International society guidelines $\cdot$ Literature review

This article is part of the Topical Collection on COVID-19

\begin{abstract}
Key Points
- Patients with confirmed SARS-CoV-2 infection within 7 days before or 30 days after surgery had an overall 30 -day mortality of $24 \%$.

- Prioritization of treatments and testing of patients prior to institutional procedures should be implemented as standard protocol.

- Radiation therapy for head-neck, nasopharyngeal, and lung fields should be actively monitored, possibly owing to the unknown effect on respiratory complications associated with COVID-19.

- Patients that have tested negative for SARC-CoV-2 are recommended to continue anticancer therapy that might be critical for tumor control.

- The risk of in-hospital COVID-19 death was significantly higher for non-hematologic malignancies diagnosed 1 to 5 years prior to SARS$\mathrm{CoV}-2$ infection and the risk for hematologic malignancies continued to remain high even after 5 years.

- Mental and physical health of clinicians should be given utmost importance as they are the ones at high risk for stress and fatigue breakdown during the pandemic.
\end{abstract}

Manit K. Gundavda

manit.gundavda@gmail.com

Kaival K. Gundavda

gundavdakaival@gmail.com
1 Department of Orthopaedic Oncology, P. D. Hinduja National Hospital and Medical Research Centre, Andheri West, Mumbai, Maharashtra 400053, India

2 Department of Surgical Oncology, Tata Memorial hospital, 93, Ground floor, Main Building, Mumbai, Maharashrta 400012, India 


\section{Introduction}

The acute pandemic of (coronavirus disease 2019) COVID-19 since its declaration in March 2020 by the World Health Organization has impacted not only medical care but most aspects of daily life. Disease spread may be intervened by physical distancing, hand and respiratory hygiene, and national stay at home guidelines.

Health systems are posed with a challenge to deliver care for diagnosed patients with cancer during this crisis, given the risks of serious complications from SARS-CoV-2 as compared with mortality from cancer. Reports with likely higher severity of COVID-19 in immunocompromised patients add the challenge $[1,2]$. Due to reasons beyond control, health care workers have struggled to deliver treatment for the patients with cancer. Reasons are not limited to lack of resources and diverting workforce towards the pandemic responseforcing hospitals to cancel or delay surgeries or limit inpatient admissions, including chemotherapy and radiation therapy. Nationwide lockdowns have limited patient's access to travel to their health care facility. The concern for otherwise healthy patients with curable cancers that require timely intervention or therapy is the risk of contracting COVID-19 may outweigh the benefits of cancer treatment [3].

Demands for personal protective equipment, greater hospital capacity, and ventilator equipped intensive care units have resulted in insufficiency in the demand need.

Transition to telemedicine has somewhat bridged the gap for in-office visits, but there is a continuing challenge of delays in cancer screening or significant decline of new diagnoses of cancers due to the pandemic [4-6]. Lack of international guidelines leaves health care providers with a case-to-case approach for delivering optimal cancer care in the wake of the pandemic. We aim to propose a balance in risk from treatment delay versus risks from COVID-19, and reviewed the publications and recommendations for cancer groups as of October 2020.

\section{Routine Precautions for Outpatients}

In addition to general guidance provided by the Centre for Disease Control (CDC), USA, emphasis in the American Society of Clinical Oncology (ASCO) for cancer patients visiting the outpatient clinics include the following [7]:

- Training for cancer patients in proper hand hygiene.

- Information regarding the symptoms of COVID-19 and minimizing exposure to sick contacts and large crowds.

- To wear a mask or cloth face cover when exposed to public or hospital environments, not necessarily a N95 mask (lack of evidence to suggest benefit in low exposure risk population).
- Most institutions implement requirements for all personnel - health care workers, patients, and visitorsto wear a surgical face mask when on campus, regardless of symptoms.

- Postponement of in-person visits if not associated with additional risk to the patient. Postponement also directed towards routine follow-up visits to assess post treatment disease status/surveillance which may be substituted with locally available investigations, self-examination, and teleconsultation.

- Screening via telemedicine for COVID-19 symptoms and exposure history ( 48 to $72 \mathrm{~h}$ prior to treatment cycles or every in-person visit) [8].

- Pro-active medical assessment for patients with symptoms of infection or fever, considering the overall higher risk of routine infections in immunocompromised cancer patients.

- For prevention of infection to other patients and health care personnel, guidelines suggest that the status of patient screening and positive COVID-19 status be documented prior admission of the patient to the institution/treatment facility [7].

Cancer Diagnosis and Staging Conservation of resource in areas where infection is an ongoing issue, the $\mathrm{CDC}$ as well as National Comprehensive Cancer Network (NCCN) and other expert guidelines recommend postponement of inperson visits for cancer screening for the general public [9-12]. Postponement of screening procedure would not only conserve resources and manpower for these facilities but also minimize patient exposure to the health care environment [13] until a time where infection spread is under control [13-16]. This also reserves facilities for patients with symptoms requiring assessment for monitoring progression or new diagnosis of cancer [17-19].

\section{Challenges in Cancer Therapy}

\section{Cancer Surgery}

Elective Surgeries Delayed/Deferred While the World Health Organization suggests that "elective surgeries" and inpatient facilities should be rescheduled unless unavoidable, individual case-based assessment on the potential outcomes from delaying essential cancer-related surgery needs to be discussed by the clinicians and their patients. Memorial Sloan Kettering Operating Room COVID-19 Subcommittee have characterized a subset of "essential cancer surgery," primarily tumor surgeries that cannot be delayed, including surgical management of brain tumors, as well as breast, colon, 
stomach, pancreas, liver, bladder, kidney, and lung resections [20].

This approach has been corroborated by the American College of Surgeons with emphasis on cases that may progress in delaying or in the absence of treatment are the ones that should be performed. This is aimed to offer a more planned procedure as compared with an emergency procedure that may arise from delay in timely surgery. Such unplanned and complicated emergencies are likely to consume more resources in the restricted setting. Another category of essential surgeries is selective palliative procedures being performed for acute relief of pain and suffering or acute neurologic deficits that are not manageable by other means [20]. Institutional protocols require the specification whether a surgical procedure will require postoperative intensive care unit (ICU) admission (planned or inadvertent complications); the decision to undertake such a procedure must be considered in conjunction with availability of ICU beds.

Neoadjuvant therapies have been used as a means of performing surgery at a later and relatively better equipped date. Neoadjuvant chemotherapy (e.g., rectal cancers), hormonal therapy (e.g., breast, prostate cancers), chemoradiotherapy (e.g., rectal, prostate cancers), or pre-operative radiotherapy (e.g., soft tissue sarcomas) as opposed to upfront surgery are possible in a spectrum of cancers as a means for delaying surgery without allowing the disease to remain unchecked [21]. However, this may not be applied as a rule, and disease management groups should weigh the risk of delay in definitive surgery against the risk of COVID-19 exposure or the probable more complex surgical resection if the tumor progresses while on interim neoadjuvant therapy [22, 23]. Neoadjuvant therapies requiring in-person visits or immunosuppressive therapies must take into account the potential incremental risks to the patient.

An international cohort study observed the outcomes of surgery during the early part of the pandemic from 1 January 2020 to 31 March 2020 and 1128 patients with confirmed SARS-CoV-2 infection within 7 days before or 30 days after surgery had an overall 30-day mortality of $24 \%$. Most common complication resulting in mortality was pulmonary complications (83\%). Mortality in adjusted analysis was associated with male sex, age $>70$ years, poorer physical status (ASA grades 3-5), malignant lesions, and emergency procedures or major procedures [24]. The poorer outcomes exceed those seen in major surgeries in the pre-COVID era. Hypotheses suggest inflammatory and prothrombotic states associated with COVID-19 severity as a result of poor surgical outcomes [25]. Therefore, this reinforces the rationale for delaying elective surgeries for limitation of viral spread, and minimizing risks, particularly of postoperative infection.

Resumption of Elective Surgeries? A joint statement from the group of surgeons, anesthesiologists, and hospital associations
[26] in USA and similar guidelines from UK [27] recommend that elective surgeries be scheduled when

- There is a persistent downward trend of SARS-CoV-2 infection rates for two or more weeks in the referral zone catered to by the hospital/institution.

- Calibration of resource distribution and return to optimal utilization of ICU bed, PPEs, and blood bank adequacy for surgery needs, over and above the requirements of the institution for catering to COVID-19 patients.

- Prioritization of surgical cases and testing of patients prior to surgery is standard protocol. Testing of employees is recommended and may be considered.

Special Precautions: Head and Neck and Upper Respiratory/ Digestive Tract Procedures Particular higher risk of droplet contact through respiratory or upper digestive tract procedures, namely diagnostic/therapeutic scopies, head-neck, and ENT surgeries [28] with safety recommendations suggesting two tests at $>24$-h intervals for SARC-CoV-2 infection prior to undertaking such procedures $[29,30]$ or exploration of alternative intervention through image/computed tomography guidance, etc., where feasible.

Radiation Therapy Consideration for receiving radiation therapy (RT) is with respect to the risk of COVID-19 exposure and may be slightly higher than the outpatient exposure associated with frequency and duration of radiation treatment, and this has been noted in the targeted response from the international radiation oncology group (Global Radiation Oncology Group) [31]. There is no independent documented risk of radiation therapy affecting COVID-19 severity or higher infection risk. However though, recommendations for certain cancers that may be placed on systemic therapy suggest delay in radiation therapy [32] or substitute with hypo-fractionated radiotherapy [33] for head-neck, nasopharyngeal, and lung fields possibly owing to the unknown effect on respiratory complications associated with COVID-19. Proceeding with radiation delivered with curative intent or for rapidly progressive tumors outweighs the risks of COVID-19 exposure and infection [34]. For active ongoing treatments, the decision to continue or delay requires careful consideration of indications, dose already delivered, and risks and benefits.

Systemic Anticancer Treatments Direct evidence to support changing or withholding systemic therapy in cancer patients is lacking [35]. Therefore, patients that have tested negative for SARC-CoV-2 are recommended to continue anticancer therapy that might be critical for tumor control. The potential harms from interrupting or delaying initiation of treatment when compared with possibility of preventing SARS-CoV- 
2-19 infection are uncertain. It is essential that an individualized decision takes into consideration patient and tumorrelated factors, namely, curability from the cancer, risk of local or distant cancer recurrence possible with delay in treatment or modification/interruption, the phase of therapy (induction or maintenance, neoadjuvant or adjuvant etc.) already completed, and the current tolerance versus the expected tolerance to systemic treatment at a later date considering some progression of disease in the absence of a therapeutic check. As discussed earlier, status of patient screening and COVID19 status be documented prior admission of the patient to the institution/treatment facility [7] at every cycle or visit for drug administration. An international collaboration of medical oncologists [36] has suggested guidelines from expert opinions that are in sync with recommendations from the National Institute for Health and Care Excellence (NICE), UK. However, lack of evidence-based guidelines requires individual centers to adapt and modify to support their health care infrastructure.

Chemotherapy Ability to isolate the chemotherapy unit from the COVID-19 care facility (patient flow as well as teams of health care workers), though challenging, may serve as a protective barrier to provide chemotherapy administration as intended. As agreed upon by multiple expert groups, treatment with curative intent would be best continued as directed by the physician with the acceptance of SARS-CoV-2 infection threat during therapy. However, an individualized treatment modification with reduction in admission duration by administering shorter duration of therapy or ensuring hydration and premedication at a local or home care facility may be implemented where feasible.

Palliative therapy alteration in the wake of COVID-19 is a fine balance with the challenges of worsening of disease status leading to deterioration of symptoms and physical performance status. Loss of opportunity to treat may be taken into account prior to modification/delay in palliative regimens [37].

ASCO recommendations [7] for chemotherapy treatment includes some of the following:

- Omission of chemotherapy in consideration of risk of COVID-19 for patients expected to have a small benefit over non-chemotherapy or non-immunosuppressive therapy (e.g.,. receptor-positive breast cancers in early stage or prostate cancers may benefit from hormonal therapy).

- Home care-assisted infusion of drugs in consultation with primary care physician, though available in certain countries $[38,39]$ may not a feasible option for infusion chemotherapy or monoclonal antibody infusions without adequate safety protocols or clinical supervision, but may be adequate to minimize admissions for need of hydration, antiemetics, etc.
- Adaptation of inpatient regimens to outpatient administration may reduce burden on hospital resources, while increasing the frequency of visits to the outpatient clinic by the patient and therefore must be judiciously considered. The NCCN toolkit is available as a guide for shifting regimens for hematological malignancies to an outpatient setting [40].

Immunotherapy: Immune Checkpoint Inhibitor Conflicting data in published literature regarding checkpoint inhibitor immunotherapy and its effect on the severity of COVID-19, especially in the instance of treatment-related pneumonitis associated with ICI, needs to be assessed in further detail [41-43].

\section{Immunomodulatory Agents: Anti-CD20 Monoclonal Antibodies}

B cell-mediated immunity has been extensively studied in the COVID-19 population, and serological evidence of antibodies as host response to SARS-CoV-2 infection has been documented [44-46]. It is therefore essential to re-evaluate the risk-benefit balance for drugs (anti-CD20 monoclonal antibodies) inhibiting $\mathrm{B}$ cells and resulting in lymphopenia $[47,48]$.

Glucocorticoids While glucocorticoid and steroidal compounds are essentials in multiple cancer therapeutic regimens, the lack of evidence-based recommendations does not justify withholding glucocorticoid use in otherwise healthy cancer patients and data regarding its effect on host immunity for the SARS-Cov-2 infection is limited [35].

\section{Type-Specific Guidelines and Literature for Cancers}

Various society guidelines and literature reports (Table 1) from study groups for specific cancer types are represented in table. An algorithmic and conceptual approach towards decision making on cancer management during the ongoing pandemic of COVID-19 requires balancing attempts between cancer progression due to treatment delay vs. risk of infection and morbidity from COVID-19. A framework for this has been proposed by an international collaborative group [49], but case-based decisions are imperative [50].

A summary compiled by an international group of international recommendations was made available in 23 languages to overcome the language barrier for dissemination of knowledge [51]. 
Table 1 Various society guidelines and literature reports from study groups for specific cancer types

\begin{tabular}{|c|c|c|}
\hline Cancer type & Society guidelines & $\begin{array}{l}\text { Literature from study } \\
\text { groups }\end{array}$ \\
\hline Breast cancer & $\begin{array}{l}\text { American College of Surgeons } \\
\text { Surgical Society of Oncology } \\
\text { American Society of Breast Surgeons } \\
\text { European Society of Medical Oncology (ESMO) } \\
\text { NCCN }\end{array}$ & {$[52-57]$} \\
\hline Gastrointestinal cancers & $\begin{array}{l}\text { American College of Surgeons } \\
\text { Surgical Society of Oncology } \\
\text { ESMO } \\
\text { NCCN } \\
\text { US Colorectal Cancer Alliance }\end{array}$ & {$[58-60]$} \\
\hline Genitourinary cancers & $\begin{array}{l}\text { ESMO } \\
\text { European Association of Urology [64] } \\
\text { Canadian Group [65] } \\
\text { British Guidelines [66] }\end{array}$ & {$[61-63]$} \\
\hline Gynecological cancers & $\begin{array}{l}\text { ESMO } \\
\text { American College of Surgeons } \\
\text { Society of Gynecologic Oncology }[71,72] \\
\text { International Gynecologic cancer society } \\
\text { American society for colposcopy and cervical pathology }\end{array}$ & {$[67-70]$} \\
\hline Head and neck cancers & $\begin{array}{l}\text { ESTRO-ASTRO [73] } \\
\text { French society-joint consensus [77] }\end{array}$ & {$[74-76]$} \\
\hline Hematologic malignancy & $\begin{array}{l}\text { American Society of Hematology } \\
\text { American Society of Transplantation and Cellular Therapy } \\
\text { European Society for Blood and Marrow Transplantation } \\
\text { ESMO } \\
\text { Australian/New Zealand consensus statement [84] } \\
\text { Brazilian task force [85] } \\
\text { International Lymphoma Radiation Oncology Group } \\
\text { International Society of Amyloidosis [86] }\end{array}$ & [78-83] \\
\hline Liver malignancy & $\begin{array}{l}\text { ESMO } \\
\text { International Liver Cancer Association } \\
\text { American Association for the Study of Liver Diseases }\end{array}$ & {$[87,88]$} \\
\hline Brain and neurological cancers & $\begin{array}{l}\text { American Association of Neurological Surgeons [89] } \\
\text { ESMO [93] }\end{array}$ & [90-92] \\
\hline $\begin{array}{l}\text { Endocrine/neuroendocrine } \\
\text { tumors }\end{array}$ & $\begin{array}{l}\text { North American Neuroendocrine Tumor Society (NANETS) } \\
\text { UK and Ireland Neuroendocrine Tumor Society } \\
\text { Society of Surgical Oncology }\end{array}$ & \\
\hline Skin cancers & $\begin{array}{l}\text { ESMO } \\
\text { Society of Surgical Oncology } \\
\text { NCCN }\end{array}$ & [94-96] \\
\hline Sarcomas & $\begin{array}{l}\text { Society of Surgical Oncology } \\
\text { ESMO } \\
\text { French Sarcoma Group [97] }\end{array}$ & \\
\hline Lung cancer & $\begin{array}{l}\text { American College of Surgeons } \\
\text { Thoracic Surgery Outcomes Research Network [100] } \\
\text { ESMO } \\
\text { International Association for the Study of Lung Cancer (IASLC) } \\
\text { NCCN }\end{array}$ & {$[98,99]$} \\
\hline
\end{tabular}


Table 1 (continued)

\begin{tabular}{lll}
\hline Cancer type & Society guidelines & $\begin{array}{l}\text { Literature from study } \\
\text { groups }\end{array}$ \\
\hline & ESTRO-ASTRO [101] & International Consensus group [9] \\
& International Society for Pediatric Oncology \\
Pediatric malignancies & Children's Oncology Group \\
& Childhood Cancer International [102] \\
& French Society for the Fight against Cancers and Leukemias in Children and Adolescents \\
& {$[103]$} \\
\hline
\end{tabular}

Cancer Survivors Limited studies have addressed the risk of COVID-19 severity and complications in patients that have received treatment for cancer, some considerations resulting from persistent immunosuppression, toxicities from systemic therapy agents, radiation-induced changes, limitation in physical activity status after major surgeries, etc., or even those on long duration of maintenance therapy [104].

- The UK group recorded national registry data adjusted for hematological and non-hematological cancers. The risk of in-hospital COVID-19 death was significantly higher for non-hematologic malignancies diagnosed 1 to 5 years prior to SARS-CoV-2 infection, and the risk for hematologic malignancies continued to remain high even after 5 years [105].

- Higher psychological and social distress resulting from isolation and distancing among cancer survivors in fear of worse COVID-19 infections may add to their overall risk to mental and physical health in adolescent and young adults [106].

\section{Cancer and Patient Support}

Prophylaxis for COVID-19 infection in the general population remains controversial without equivocal evidence to suggest for or against the use of certain agents (e.g., hydroxychloroquine, antiviral compounds, etc). The use of specific antiviral agents as prophylaxis for the immunocompromised subset of patients undergoing cancer therapy remains ambiguous too.

- Supportive care includes care of chemoports which may be over intervals as long as 10 to 12 weeks (as compared with the routine 4-6-week schedule) [107], with the possibility of trained home care personnel providing aseptic port care without requiring visit to the hospital facility.
- Scarcity of blood donations and increased demand for blood transfusions for COVID-19 patients with severe disease may lead to a shortage of blood and bloodproduct availability for cancer patients receiving therapy. Anticipation and pre-emptive stimulation with erythropoietin stimulation/colony-stimulating factors may be administered. Anemia from bleeding may need aggressive intervention with embolization, etc.

- Relatively staged surgical procedures may offer the patients an opportunity to arrange for donor transfusions from family and friends to sustain or replenish the personal requirement.

- In patients with advanced cancer, counseling and documentation of the counseling for end-of-life preferences and physicians orders for life-sustaining treatment (POLST) must be carried out in the event the cancer or COVID-19 may affect the other, worsening outcomes and chances of survival [108, 109].

- Pneumonitis associated with medica agents (checkpoint inhibitor immunotherapies, gemcitabine, etc.) needs to be assessed and differentiated from COVID19 symptoms. COVID-19 testing should be recommended in any event of suspicion. Lymphangitic spread, radiation pneumonitis, and lung infiltrates may also resemble respiratory changes associated with COVID-19 [110]. Need for this distinction is essential due to inadequate data on worsening of pneumonitis in COVID-19 to vice versa.

- Deferred treatment in the wake of the pandemic may lead to vulnerability in cancer patients that are already anxious and fearful of disease progression or local/distant recurrences. Social isolation combined with mixed depression and anger from constrained resources and helplessness needs to be identified and addressed by counseling/ education and reassurance by reaching out through telemedicine [111, 112].

- Stress and anxiety are not only limited to the patients but also affect the clinicians isolating from family and friends, 
exceedingly demanding work schedules and challenges in patient care [113]. There is therefore a need for resources to help and enhance the physical and mental health of frontline workers.

\section{Summary}

- It is imperative to balance the result of delayed cancer therapy as compared with risk of COVID-19 in the potential increased vulnerable population with cancer.

- SARS-CoV-2 infection does not interfere with, nor does it have an effect on the diagnosis or staging of cancer as available from current evidence.

- Elective surgeries may be delayed with staged treatment strategies in attempt to conserve of resources, limit exposure to hospital and high viral environment thereby minimizing risks, particularly of postoperative infection which may be life threatening.

- There is no direct evidence to support changing or withholding radiotherapy, chemotherapy, or immunotherapy in patients with cancer, and routinely withholding critical anticancer or potentially immunosuppressive therapy is not recommended for those who do not have COVID-19.

- Port care may be available at local/home facilities and at extended intervals as is documented to be effective as well as safe.

- Patients with advanced cancer who are at elevated risk for COVID-19 must be counseled for end-of-life choices and POLST.

- Teleconsultations for routine follow-up and disease surveillance may be implemented. In-person visits required for physical examination, investigations, etc., need to be streamlined with physical distancing, minimal waiting times, limiting accompanying persons, and visits to emergency for care that may be available locally.

- Guidelines on use of face masks must be implemented as a rule for all persons, at least within the hospital campus. Identification of risk zones/procedures and recommendations for risk-specific PPE use should allow optimal use of limited resources.

- Mental and physical health of clinicians should be given utmost importance as they are the ones at high risk for stress and fatigue breakdown during the pandemic.

\footnotetext{
Author Contributions Manit K. Gundavda and Kaival K. Gundavda contribution: concepts, design, definition of intellectual content, literature search, data acquisition, data analysis, statistical analysis, manuscript preparation, and manuscript editing and review.
}

Data Availability Not applicable.

\section{Compliance with Ethical Standards}

Conflict of Interest The authors declare that they have no conflict of interest.

Ethics Approval Not applicable, no patient data presented.

Consent to Participate Not applicable.

Consent for Publication Not applicable.

Code Availability Not applicable.

\section{References}

1. Lewis MA. Between scylla and charybdis - oncologic decision making in the time of Covid-19. N Engl J Med. 2020;382(24): 2285-7. https://doi.org/10.1056/NEJMp2006588.

2. Yu J, Ouyang W, Chua MLK, Xie C. SARS-CoV-2 transmission in patients with cancer at a tertiary care hospital in Wuhan. China JAMA Oncol. 2020;6(7):1108-10. https://doi.org/10.1001/ jamaoncol.2020.0980.

3. Cannistra SA, Haffty BG, Ballman K. Challenges faced by medical journals during the COVID-19 pandemic. J Clin Oncol. 2020;38(19):2206-7. https://doi.org/10.1200/jco.20.00858.

4. Dinmohamed AG, Visser O, Verhoeven RHA, Louwman MWJ, van Nederveen FH, Willems SM, et al. Fewer cancer diagnoses during the COVID-19 epidemic in the Netherlands. Lancet Oncol. 2020;21(6):750-1. https://doi.org/10.1016/s1470-2045(20) 30265-5.

5. Kaufman HW, Chen Z, Niles J, Fesko Y. Changes in the number of US patients with newly identified cancer before and during the coronavirus disease 2019 (COVID-19) pandemic. JAMA Netw Open. 2020;3(8):e2017267. https://doi.org/10.1001/ jamanetworkopen.2020.17267.

6. London JW, Fazio-Eynullayeva E, Palchuk MB, Sankey P, McNair C. Effects of the COVID-19 pandemic on cancer-related patient encounters. JCO Clin Cancer Informat. 2020;4:657-65. https://doi.org/10.1200/cci.20.00068.

7. ASCO Special report: Guide to cancer care delivery during the COVID-19 pandemic. http://www.asco.org/sites/new-www.asco. org/files/content-files/2020- ASCO-Guide-Cancer-COVID19. pdf. Accessed 31 May 2020

8. Cinar P, Kubal T, Freifeld A, Mishra A, Shulman L, Bachman J, et al. Safety at the time of the COVID-19 pandemic: how to keep our oncology patients and healthcare workers safe. J Natl Compr Cancer Netw : JNCCN. 2020:1-6. https://doi.org/10.6004/jnccn. 2020.7572

9. Mazzone PJ, Gould MK, Arenberg DA, Chen AC, Choi HK, Detterbeck FC, et al. Management of lung nodules and lung cancer screening during the COVID-19 pandemic: CHEST Expert Panel Report. Chest. 2020;158(1):406-15. https://doi.org/10. 1016/j.chest.2020.04.020.

10. Ciavattini A, Delli Carpini G, Giannella L, De Vincenzo R, Frega A, Cattani P, et al. Expert consensus from the Italian Society for Colposcopy and Cervico-Vaginal Pathology (SICPCV) for colposcopy and outpatient surgery of the lower genital tract during the COVID-19 pandemic. Int J Gynaecol Obstet. 2020;149(3): 269-72. https://doi.org/10.1002/ijgo.13158.

11. Villani A, Fabbrocini G, Costa C, Scalvenzi M. Melanoma screening days during the coronavirus disease 2019 (COVID-19) 
pandemic: strategies to adopt. Dermatol Ther. 2020;10(4):525-7. https://doi.org/10.1007/s13555-020-00402-X.

12. Ceugnart L, Delaloge S, Balleyguier C, Deghaye M, Veron L, Kaufmanis A, et al. Breast cancer screening and diagnosis at the end of the COVID-19 confinement period, practical aspects and prioritization rules: recommendations of 6 French health professionals societies. Bull Cancer. 2020;107(6):623-8. https://doi.org/ 10.1016/j.bulcan.2020.04.006.

13. Jones D, Neal RD, Duffy SRG, Scott SE, Whitaker KL, Brain K. Impact of the COVID-19 pandemic on the symptomatic diagnosis of cancer: the view from primary care. Lancet Oncol. 2020;21(6): 748-50. https://doi.org/10.1016/s1470-2045(20)30242-4.

14. Gralnek IM, Hassan C, Dinis-Ribeiro M. COVID-19 and endoscopy: implications for healthcare and digestive cancer screening. Nat Rev Gastroenterol Hepatol. 2020;17(8):444-6. https://doi.org/ 10.1038/s41575-020-0312-x.

15. Tan KK, Lau J. Cessation of cancer screening: an unseen cost of the COVID-19 pandemic? Eur J Surg Oncol. 2020. https://doi.org/ 10.1016/j.ejso.2020.05.004.

16. Amit M, Tam S, Bader T, Sorkin A, Benov A. Pausing cancer screening during the severe acute respiratory syndrome coronavirus 2pandemic: should we revisit the recommendations? Eur J Cancer (Oxford, England : 1990). 2020;134:86-9. https://doi. org/10.1016/j.ejca.2020.04.016.

17. Neal RD, Nekhlyudov L, Wheatstone P, Koczwara B. Cancer care during and after the pandemic. BMJ (Clinical research ed). 2020;370:m2622. https://doi.org/10.1136/bmj.m2622.

18. Maida M. Screening of gastrointestinal cancers during COVID19: a new emergency. Lancet Oncol. 2020;21(7):e338. https://doi. org/10.1016/s1470-2045(20)30341-7.

19. Helsper CW, Campbell C, Emery J, Neal RD, Li L, Rubin G, et al. Cancer has not gone away: a primary care perspective to support a balanced approach for timely cancer diagnosis during COVID- 19 . Eur J Cancer Care. 2020:e13290. https://doi.org/10.1111/ecc. 13290.

20. Cancer Surgery and COVID19. Ann Surg Oncol. 2020;27(6): 1713-6. https://doi.org/10.1245/s10434-020-08462-1.

21. Thompson CK, Lee MK, Baker JL, Attai DJ, DiNome ML. Taking a second look at neoadjuvant endocrine therapy for the treatment of early stage estrogen receptor positive breast cancer during the COVID-19 outbreak. Ann Surg. 2020. https://doi.org/ 10.1097/sla.0000000000004027.

22. Sud A, Jones ME, Broggio J, Loveday C, Torr B, Garrett A, et al. Collateral damage: the impact on outcomes from cancer surgery of the COVID-19 pandemic. Ann Oncol. 2020;31(8):1065-74. https://doi.org/10.1016/j.annonc.2020.05.009.

23. Fligor SC, Wang S, Allar BG, Tsikis ST, Ore AS, Whitlock AE, et al. Gastrointestinal malignancies and the COVID-19 pandemic: evidence-based triage to surgery. J Gastrointest Surg. 2020:1-17. https://doi.org/10.1007/s11605-020-04712-5.

24. Mortality and pulmonary complications in patients undergoing surgery with perioperative SARS-CoV-2 infection: an international cohort study. Lancet. 2020;396(10243):27-38. https://doi.org/ 10.1016/s0140-6736(20)31182-x.

25. Myles PS, Maswime S. Mitigating the risks of surgery during the COVID-19 pandemic. Lancet. 2020;396(10243):2-3. https://doi. org/10.1016/s0140-6736(20)31256-3.

26. Joint Statement: Roadmap for resuming elective surgery after COVID-19 pandemic. American College of Surgeons, American Society of Anesthesiologists, Association of periOperative Registered Nurses, American Hospital Association. April 17, 2020. Available at: https://www.facs.org/covid-19/clinicalguidance/roadmap-elective-surgery. Accessed 25 April 2020.

27. Cancer Research UK. Priorities for the UK governments and health services to recover cancer services through and beyond the COVID-19 pandemic. http://www.cancerresearchuk.org/ sites/default/files/cruk_priorities_for_recovery_of_cancer services.pdf. Accessed June 2020.

28. Garcia-Doval I. Head and neck surgery is a high-risk procedure for COVID-19 transmission, and there is a need for a preventive strategy to protect professionals. J Am Acad Dermatol. 2020;83(2): 705-6. https://doi.org/10.1016/j.jaad.2020.05.061.

29. Givi B, Schiff BA, Chinn SB, Clayburgh D, Iyer NG, Jalisi S, et al. Safety Recommendations for evaluation and surgery of the head and neck during the COVID-19 pandemic. JAMA Otolaryngol Head Neck Surg. 2020. https://doi.org/10.1001/ jamaoto.2020.0780.

30. Mehanna H, Hardman JC, Shenson JA, Abou-Foul AK, Topf MC, AlFalasi M, et al. Recommendations for head and neck surgical oncology practice in a setting of acute severe resource constraint during the COVID-19 pandemic: an international consensus. Lancet Oncol. 2020;21(7):e350-e9. https://doi.org/10.1016/ s1470-2045(20)30334-x.

31. Simcock R, Thomas TV, Estes C, Filippi AR, Katz MA, Pereira IJ, et al. COVID-19: Global radiation oncology's targeted response for pandemic preparedness. Clin Transl Radiat Oncol. 2020;22:55-68. https://doi.org/10.1016/j.ctro.2020.03.009.

32. Muralidhar V, Dee EC, D'Amico AV. Sequencing treatments for cancer during the COVID-19 pandemic. Am J Clin Oncol. $2020 ; 43(7): 457-8$. https://doi.org/10.1097/coc. 0000000000000717 .

33. Huang SH, O'Sullivan B, Su J, Ringash J, Bratman SV, Kim J, et al. Hypofractionated radiotherapy alone with 2.4 Gy per fraction for head and neck cancer during the COVID-19 pandemic: The Princess Margaret experience and proposal. Cancer. 2020;126(15):3426-37. https://doi.org/10.1002/cncr.32968.

34. Nagar H, Formenti SC. Cancer and COVID-19 - potentially deleterious effects of delaying radiotherapy. Nat Rev Clin Oncol. 2020;17(6):332-4. https://doi.org/10.1038/s41571-020-0375-1.

35. Russell B, Moss C, George G, Santaolalla A, Cope A, Papa S, et al. Associations between immune-suppressive and stimulating drugs and novel COVID-19-a systematic review of current evidence. Ecancermedicalscience. 2020;14:1022. https://doi.org/10. 3332/ecancer.2020.1022.

36. Segelov E, Underhill C, Prenen H, Karapetis C, Jackson C, Nott L, et al. Practical considerations for treating patients with cancer in the COVID-19 pandemic. JCO Oncol Pract. 2020;16(8):467-82. https://doi.org/10.1200/op.20.00229.

37. Ueda M, Martins R, Hendrie PC, McDonnell T, Crews JR, Wong TL, et al. Managing cancer care during the COVID-19 pandemic: agility and collaboration toward a common goal. J Natl Compr Cancer Netw : JNCCN. 2020:1-4. https://doi.org/10.6004/jnccn. 2020.7560 .

38. Murthy V, Wilson J, Suhr J, James L, Tombs H, Shereef E, et al. Moving cancer care closer to home: a single-centre experience of home chemotherapy administration for patients with myelodysplastic syndrome. ESMO Open. 2019;4(2):e000434. https://doi.org/10.1136/esmoopen-2018-000434.

39. Depledge J. Chemotherapy in the community for adult patients with cancer. Br J Community Nurs. 2012;17(5):214-20. https:// doi.org/10.12968/bjen.2012.17.5.214.

40. National Comprehensive Cancer Network (NCCN). NCCN Best Practices Committee Infusion Efficiency Workgroup. Toolkit: providing oncology treatments in the outpatient setting. http:// www.nccn.org/covid-19/pdf/NCCN_Toolkit_Updated_for COVID-19.pdf. Accessed 10 June 2020.

41. Di Giacomo AM, Gambale E, Monterisi S, Valente M, Maio M. SARS-COV-2 infection in patients with cancer undergoing checkpoint blockade: clinical course and outcome. Eur J Cancer (Oxford, England : 1990). 2020;133:1-3. https://doi.org/10. 1016/j.ejca.2020.04.026. 
42. Maio M, Hamid O, Larkin J, Covre A, Altomonte M, Calabrò L, et al. Immune checkpoint inhibitors for cancer therapy in the COVID-19 era. Clin Cancer Res. 2020;26(16):4201-5. https:// doi.org/10.1158/1078-0432.ccr-20-1657.

43. Souza IL, Fernandes Í, Taranto P, Buzaid AC, Schvartsman G. Immune-related pneumonitis with nivolumab and ipilimumab during the coronavirus disease 2019 (COVID-19) pandemic. Eur J Cancer (Oxford, England : 1990). 2020;135:147-9. https://doi. org/10.1016/j.ejca.2020.06.004.

44. Zhou F, Yu T, Du R, Fan G, Liu Y, Liu Z, et al. Clinical course and risk factors for mortality of adult inpatients with COVID-19 in Wuhan, China: a retrospective cohort study. Lancet. 2020;395(10229):1054-62. https://doi.org/10.1016/s01406736(20)30566-3.

45. Guan WJ, Ni ZY, Hu Y, Liang WH, Ou CQ, He JX, et al. Clinical characteristics of coronavirus disease 2019 in China. N Engl J Med. 2020;382(18):1708-20. https://doi.org/10.1056/ NEJMoa2002032.

46. Terpos E, Ntanasis-Stathopoulos I, Elalamy I, Kastritis E, Sergentanis TN, Politou M, et al. Hematological findings and complications of COVID-19. Am J Hematol. 2020;95(7):834 47. https://doi.org/10.1002/ajh.25829.

47. Yarza R, Bover M, Paredes D, López-López F, Jara-Casas D, Castelo-Loureiro A, et al. SARS-CoV-2 infection in cancer patients undergoing active treatment: analysis of clinical features and predictive factors for severe respiratory failure and death. Eur J Cancer (Oxford, England : 1990). 2020;135:242-50. https://doi. org/10.1016/j.ejca.2020.06.001.

48. Shah V, Ko Ko T, Zuckerman M, Vidler J, Sharif S, Mehra V, et al. Poor outcome and prolonged persistence of SARS-CoV-2 RNA in COVID-19 patients with haematological malignancies; King's College Hospital experience. Br J Haematol. 2020. https://doi.org/10.1111/bjh.16935.

49. Al-Shamsi HO, Alhazzani W, Alhuraiji A, Coomes EA, Chemaly $\mathrm{RF}$, Almuhanna M, et al. A practical approach to the management of cancer patients during the novel coronavirus disease 2019 (COVID-19) pandemic: an International Collaborative Group. Oncologist. 2020;25(6):e936-e45. https://doi.org/10.1634/ theoncologist.2020-0213.

50. Kutikov A, Weinberg DS, Edelman MJ, Horwitz EM, Uzzo RG, Fisher RI. A war on two fronts: cancer care in the time of COVID19. Ann Intern Med. 2020;172(11):756-8. https://doi.org/10. 7326/m20-1133.

51. Mauri D, Kamposioras K, Tolia M, Alongi F, Tzachanis D. Summary of international recommendations in 23 languages for patients with cancer during the COVID-19 pandemic. Lancet Oncol. 2020;21(6):759-60. https://doi.org/10.1016/s14702045(20)30278-3.

52. Coles CE, Aristei C, Bliss J, Boersma L, Brunt AM, Chatterjee S, et al. International Guidelines on Radiation Therapy for Breast Cancer During the COVID-19 Pandemic. Clin Oncol (Royal College of Radiologists (Great Britain)). 2020;32(5):279-81. https://doi.org/10.1016/j.clon.2020.03.006.

53. Dietz JR, Moran MS, Isakoff SJ, Kurtzman SH, Willey SC, Burstein $\mathrm{HJ}$, et al. Recommendations for prioritization, treatment, and triage of breast cancer patients during the COVID-19 pandemic. the COVID-19 pandemic breast cancer consortium. Breast Cancer Res Treat. 2020;181(3):487-97. https://doi.org/ 10.1007/s10549-020-05644-z.

54. Curigliano G, Cardoso MJ, Poortmans P, Gentilini O, Pravettoni G, Mazzocco K, et al. Recommendations for triage, prioritization and treatment of breast cancer patients during the COVID-19 pandemic. Breast (Edinburgh, Scotland). 2020;52:8-16. https://doi. org/10.1016/j.breast.2020.04.006.

55. Dowsett M, Ellis MJ, Dixon JM, Gluz O, Robertson J, Kates R, et al. Evidence-based guidelines for managing patients with primary ER+ HER2- breast cancer deferred from surgery due to the COVID-19 pandemic. NPJ Breast Cancer. 2020;6:21. https:// doi.org/10.1038/s41523-020-0168-9.

56. Sheng JY, Santa-Maria CA, Mangini N, Norman H, Couzi R, Nunes R. et al., Management of breast cancer during the COVID-19 pandemic: a stage- and subtype-specific approach. JCO Oncol Pract. 2020:Op2000364. https://doi.org/10.1200/op. 20.00364.

57. Freedman RA, Sedrak MS, Bellon JR, Block CC, Lin NU, King TA, et al. Weathering the storm: managing older adults with breast cancer amid COVID-19 and beyond. J Natl Cancer Inst. 2020. https://doi.org/10.1093/jnci/djaa079.

58. Lou E, Beg S, Bergsland E, Eng C, Khorana A, Kopetz S, et al. Modifying practices in GI oncology in the face of COVID-19: recommendations from expert oncologists on minimizing patient risk. JCO Oncol Pract. 2020;16(7):383-8. https://doi.org/10.1200/ op.20.00239.

59. O'Leary MP, Choong KC, Thornblade LW, Fakih MG, Fong Y, Kaiser AM. Management considerations for the surgical treatment of colorectal cancer during the global Covid-19 pandemic. Ann Surg. 2020;272(2):e98-e105. https://doi.org/10.1097/sla. 0000000000004029 .

60. Jones CM, Radhakrishna G, Aitken K, Bridgewater J, Corrie P, Eatock M, et al. Considerations for the treatment of pancreatic cancer during the COVID-19 pandemic: the UK consensus position. Br J Cancer. 2020;123(5):709-13. https://doi.org/10.1038/ s41416-020-0980-x.

61. Wallis CJD, Novara G, Marandino L, Bex A, Kamat AM, Karnes $\mathrm{RJ}$, et al. Risks from deferring treatment for genitourinary cancers: a collaborative review to aid triage and management during the COVID-19 pandemic. Eur Urol. 2020;78(1):29-42. https://doi. org/10.1016/j.eururo.2020.04.063.

62. Stensland KD, Morgan TM, Moinzadeh A, Lee CT, Briganti A, Catto JWF, et al. Considerations in the triage of urologic surgeries during the COVID-19 pandemic. Eur Urol. 2020;77(6):663-6. https://doi.org/10.1016/j.eururo.2020.03.027.

63. Goldman HB, Haber GP. Recommendations for tiered stratification of urological surgery urgency in the COVID-19 era. J Urol. $2020 ; 204$ (1): 11-3. https://doi.org/10.1097/ju. 0000000000001067

64. Ribal MJ, Cornford P, Briganti A, Knoll T, Gravas S, Babjuk M, et al. European Association of Urology Guidelines Office Rapid Reaction Group: an organisation-wide collaborative effort to adapt the European Association of Urology Guidelines Recommendations to the coronavirus disease 2019 era. Eur Urol. 2020;78(1):21-8. https://doi.org/10.1016/j.eururo.2020.04. 056.

65. Kokorovic A, So AI, Hotte SJ, Black PC, Danielson B, Emmenegger U, et al. A Canadian framework for managing prostate cancer during the COVID-19 pandemic: recommendations from the Canadian Urologic Oncology Group and the Canadian Urological Association. Can Urol Assoc J. 2020;14(6):163-8. https://doi.org/10.5489/cuaj.6667.

66. Gillessen S, Powles T. Advice regarding systemic therapy in patients with urological cancers during the COVID-19 pandemic. Eur Urol. 2020;77(6):667-8. https://doi.org/10.1016/j.eururo. 2020.03.026.

67. Akladios C, Azais H, Ballester M, Bendifallah S, Bolze PA, Bourdel N, et al. Recommendations for the surgical management of gynecological cancers during the COVID-19 pandemicFRANCOGYN group for the CNGOF. J Gynecol Obstetr Hum Reprod. 2020;49(6):101729. https://doi.org/10.1016/j.jogoh. 2020.101729.

68. Ramirez PT, Chiva L, Eriksson AGZ, Frumovitz M, Fagotti A, Gonzalez Martin A, et al. COVID-19 global pandemic: options for 
management of gynecologic cancers. Int J Gynecol Cancer. 2020;30(5):561-3. https://doi.org/10.1136/ijgc-2020-001419.

69. Elledge CR, Beriwal S, Chargari C, Chopra S, Erickson BA, Gaffney DK, et al. Radiation therapy for gynecologic malignancies during the COVID-19 pandemic: international expert consensus recommendations. Gynecol Oncol. 2020;158(2):244-53. https://doi.org/10.1016/j.ygyno.2020.06.486.

70. Uwins C, Bhandoria GP, Shylasree TS, Butler-Manuel S, Ellis P, Chatterjee J, et al. COVID-19 and gynecological cancer: a review of the published guidelines. Int J Gynecol Cancer. 2020. https:// doi.org/10.1136/ijgc-2020-001634.

71. Pothuri B, Alvarez Secord A, Armstrong DK, Chan J, Fader AN, Huh W, et al. Anti-cancer therapy and clinical trial considerations for gynecologic oncology patients during the COVID-19 pandemic crisis. Gynecol Oncol. 2020;158(1):16-24. https://doi.org/10. 1016/j.ygyno.2020.04.694

72. Fader AN, Huh WK, Kesterson J, Pothuri B, Wethington S, Wright JD, et al. When to operate, hesitate and reintegrate: society of gynecologic oncology surgical considerations during the COVID-19 pandemic. Gynecol Oncol. 2020;158(2):236-43. https://doi.org/10.1016/j.ygyno.2020.06.001.

73. Thomson DJ, Palma D, Guckenberger M, Balermpas P, Beitler JJ, Blanchard P, et al. Practice recommendations for risk-adapted head and neck cancer radiation therapy during the COVID-19 pandemic: an ASTRO-ESTRO Consensus Statement. Int J Radiat Oncol Biol Phys. 2020;107(4):618-27. https://doi.org/10. 1016/j.ijrobp.2020.04.016.

74. Maniakas A, Jozaghi Y, Zafereo ME, Sturgis EM, Su SY, Gillenwater AM, et al. Head and neck surgical oncology in the time of a pandemic: subsite-specific triage guidelines during the COVID-19 pandemic. Head Neck. 2020;42(6):1194-201. https:// doi.org/10.1002/hed.26206.

75. Topf MC, Shenson JA, Holsinger FC, Wald SH, Cianfichi LJ, Rosenthal EL, et al. Framework for prioritizing head and neck surgery during the COVID-19 pandemic. Head Neck. 2020;42(6):1159-67. https://doi.org/10.1002/hed.26184.

76. Paleri V, Hardman J, Tikka T, Bradley P, Pracy P, Kerawala C. Rapid implementation of an evidence-based remote triaging system for assessment of suspected referrals and patients with head and neck cancer on follow-up after treatment during the COVID19 pandemic: model for international collaboration. Head Neck. 2020;42(7):1674-80. https://doi.org/10.1002/hed.26219.

77. Fakhry N, Schultz P, Morinière S, Breuskin I, Bozec A, Vergez S, et al. French consensus on management of head and neck cancer surgery during COVID-19 pandemic. Eur Ann Otorhinolaryngol Head Neck Dis. 2020;137(3):159-60. https://doi.org/10.1016/j. anorl.2020.04.008.

78. Percival MM, Lynch RC, Halpern AB, Shadman M, Cassaday $\mathrm{RD}$, Ujjani $\mathrm{C}$, et al. Considerations for managing patients with hematologic malignancy during the COVID-19 pandemic: The Seattle Strategy. JCO Oncol Pract. 2020:Op2000241. https://doi. org/10.1200/op.20.00241.

79. Mian H, Grant SJ, Engelhardt M, Pawlyn C, Bringhen S, Zweegman S, et al. Caring for older adults with multiple myeloma during the COVID-19 Pandemic: perspective from the International Forum for Optimizing Care of Older Adults with Myeloma. J Geriatr Oncol. 2020;11(5):764-8. https://doi.org/10. 1016/j.jgo.2020.04.008.

80. Terpos E, Engelhardt M, Cook G, Gay F, Mateos MV, NtanasisStathopoulos I, et al. Management of patients with multiple myeloma in the era of COVID-19 pandemic: a consensus paper from the European Myeloma Network (EMN). Leukemia. 2020;34(8): 2000-11. https://doi.org/10.1038/s41375-020-0876-z.

81. Al Saleh AS, Sher T, Gertz MA. Multiple myeloma in the time of COVID-19. Acta Haematol. 2020:1-7. https://doi.org/10.1159/ 000507690 .
82. Zic JA, Ai W, Akilov OE, Carter JB, Duvic M, Foss F. United States Cutaneous Lymphoma Consortium recommendations for treatment of cutaneous lymphomas during the COVID-19 pandemic. J Am Acad Dermatol. et al., 2020;83(2):703-4. https:// doi.org/10.1016/j.jaad.2020.04.049.

83. Papadavid E, Scaribrick J, Ortiz Romero P, Guaglino P, Vermeer $\mathrm{M}$, Knobler R, et al. Management of primary cutaneous lymphoma patients during COVID-19 pandemic: EORTC CLTF guidelines. J Eur Acad Dermatol Venereol : JEADV. 2020;34(8):16336. https://doi.org/10.1111/jdv.16593.

84. Di Ciaccio P, McCaughan G, Trotman J, Ho PJ, Cheah CY, Gangatharan S, et al. Australian and New Zealand consensus statement on the management of lymphoma, chronic lymphocytic leukaemia and myeloma during the COVID-19 pandemic. Intern Med J. 2020;50(6):667-79. https://doi.org/10.1111/imj.14859.

85. Perini GF, Fischer T, Gaiolla RD, Rocha TB, Bellesso M, Teixeira LLC, et al. How to manage lymphoid malignancies during novel 2019 coronavirus (CoVid-19) outbreak: a Brazilian task force recommendation. Hematol Transfusion Cell Ther. 2020;42(2):10310. https://doi.org/10.1016/j.htct.2020.04.002.

86. Kastritis E, Wechalekar A, Schönland S, Sanchorawala V, Merlini G, Palladini G, et al. Challenges in the management of patients with systemic light chain (AL) amyloidosis during the COVID-19 pandemic. Br J Haematol. 2020;190(3):346-57. https://doi.org/ 10.1111/bjh.16898.

87. Ganne-Carrié N, Fontaine H, Dumortier J, Boursier J, Bureau C, Leroy V, et al. Suggestions for the care of patients with liver disease during the coronavirus 2019 pandemic. Clin Res Hepatol Gastroenterol. 2020;44(3):275-81. https://doi.org/10.1016/j. clinre.2020.04.001.

88. Barry A, Apisarnthanarax S, O'Kane GM, Sapisochin G, Beecroft $\mathrm{R}$, Salem R, et al. Management of primary hepatic malignancies during the COVID-19 pandemic: recommendations for risk mitigation from a multidisciplinary perspective. Lancet Gastroenterol Hepatol. 2020;5(8):765-75. https://doi.org/10.1016/s24681253(20)30182-5.

89. Ramakrishna R, Zadeh G, Sheehan JP, Aghi MK. Inpatient and outpatient case prioritization for patients with neuro-oncologic disease amid the COVID-19 pandemic: general guidance for neuro-oncology practitioners from the AANS/CNS Tumor Section and Society for Neuro-Oncology. J Neuro-Oncol. 2020;147(3):525-9. https://doi.org/10.1007/s11060-020-034887.

90. Mohile NA, Blakeley JO, Gatson NTN, Hottinger AF, Lassman $A B$, Ney DE, et al. Urgent considerations for the neuro-oncologic treatment of patients with gliomas during the COVID-19 pandemic. Neuro-oncology. 2020;22(7):912-7. https://doi.org/10.1093/ neuonc/noaa090.

91. Bernhardt D, Wick W, Weiss SE, Sahgal A, Lo SS, Suh JH, et al. Neuro-oncology management during the COVID-19 pandemic with a focus on WHO grade III and IV gliomas. Neuro-oncology. 2020;22(7):928-35. https://doi.org/10.1093/neuonc/noaa113.

92. Tabrizi S, Trippa L, Cagney D, Tanguturi S, Ventz S, Fell G, et al. A quantitative framework for modeling COVID-19 risk during adjuvant therapy using published randomized trials of glioblastoma in the elderly. Neuro-oncology. 2020;22(7):918-27. https:// doi.org/10.1093/neuonc/noaa111.

93. Weller M, Preusser M. How we treat patients with brain tumour during the COVID-19 pandemic. ESMO Open. 2020;4(Suppl 2). https://doi.org/10.1136/esmoopen-2020-000789.

94. Nahm SH, Rembielak A, Peach H, Lorigan PC. Consensus guidelines for the management of melanoma during the COVID-19 pandemic: surgery, systemic anti-cancer therapy, radiotherapy and follow-up. Clin Oncol (Royal College of Radiologists (Great Britain)). 2020. https://doi.org/10.1016/j.clon.2020.06.017. 
95. Tagliaferri L, Di Stefani A, Schinzari G, Fionda B, Rossi E, Del Regno L, et al. Skin cancer triage and management during COVID-19 pandemic. J Eur Acad Dermatol Venereol : JEADV. 2020;34(6):1136-9. https://doi.org/10.1111/jdv.16529.

96. Baumann BC, MacArthur KM, Brewer JD, Mendenhall WM, Barker CA, Etzkorn JR, et al. Management of primary skin cancer during a pandemic: multidisciplinary recommendations. Cancer. 2020;126(17):3900-6. https://doi.org/10.1002/cncr.32969.

97. Penel N, Bonvalot S, Minard V, Orbach D, Gouin F, Corradini N, et al. French Sarcoma Group proposals for management of sarcoma patients during the COVID-19 outbreak. Ann Oncol. 2020;31(7):965-6. https://doi.org/10.1016/j.annonc.2020.03.308.

98. Dingemans AC, Soo RA, Jazieh AR, Rice SJ, Kim YT, Teo LLS, et al. Treatment guidance for patients with lung cancer during the coronavirus 2019 pandemic. J Thorac Oncol. 2020;15(7):111936. https://doi.org/10.1016/j.jtho.2020.05.001.

99. Singh AP, Berman AT, Marmarelis ME, Haas AR, Feigenberg SJ, Braun J, et al. Management of lung cancer during the COVID-19 pandemic. JCO Oncol Pract. 2020:Op2000286. https://doi.org/10. 1200/op.20.00286.

100. Antonoff M, Backhus L, Boffa DJ, Broderick SR, Brown LM, Carrott P, et al. COVID-19 guidance for triage of operations for thoracic malignancies: a consensus statement from Thoracic Surgery Outcomes Research Network. Ann Thorac Surg. 2020;110(2):692-6. https://doi.org/10.1016/j.athoracsur.2020.03. 005 .

101. Guckenberger M, Belka C, Bezjak A, Bradley J, Daly ME, DeRuysscher D, et al. Practice recommendations for lung cancer radiotherapy during the COVID-19 pandemic: An ESTROASTRO consensus statement. Radiother Oncol. 2020;146:2239. https://doi.org/10.1016/j.radonc.2020.04.001.

102. Bouffet E, Challinor J, Sullivan M, Biondi A, Rodriguez-Galindo C, Pritchard-Jones K. Early advice on managing children with cancer during the COVID-19 pandemic and a call for sharing experiences. Pediatr Blood Cancer. 2020;67(7):e28327. https:// doi.org/10.1002/pbc.28327.

103. Baruchel A, Bertrand Y, Boissel N, Brethon B, Ducassou S, Gandemer V, et al. COVID-19 and acute lymphoblastic leukemias of children and adolescents: First recommendations of the Leukemia committee of the French Society for the fight against Cancers and Leukemias in children and adolescents (SFCE). Bull Cancer. 2020;107(6):629-32. https://doi.org/10.1016/j.bulcan. 2020.04.003
104. Kuderer NM, Choueiri TK, Shah DP, Shyr Y, Rubinstein SM, Rivera DR, et al. Clinical impact of COVID-19 on patients with cancer (CCC19): a cohort study. Lancet. 2020;395(10241):190718. https://doi.org/10.1016/s0140-6736(20)31187-9.

105. Williamson EJ, Walker AJ, Bhaskaran K, Bacon S, Bates C, Morton CE, et al. Factors associated with COVID-19-related death using OpenSAFELY. Nature. 2020;584(7821):430-6. https://doi.org/10.1038/s41586-020-2521-4.

106. Košir U, Loades M, Wild J, Wiedemann M, Krajnc A, Roškar S, et al. The impact of COVID-19 on the cancer care of adolescents and young adults and their well-being: Results from an online survey conducted in the early stages of the pandemic. Cancer. 2020. https://doi.org/10.1002/cncr.33098.

107. Diaz JA, Rai SN, Wu X, Chao JH, Dias AL, Kloecker GH. Phase II trial on extending the maintenance flushing interval of implanted ports. J Oncol Pract. 2017;13(1):e22-e8. https://doi.org/ 10.1200/jop.2016.010843.

108. Curtis JR, Kross EK, Stapleton RD. The importance of addressing advance care planning and decisions about do-not-resuscitate orders during novel coronavirus 2019 (COVID-19). Jama. 2020. https://doi.org/10.1001/jama.2020.4894.

109. Holstead RG, Robinson AG. Discussing serious news remotely: navigating difficult conversations during a pandemic. JCO Oncol Pract. 2020;16(7):363-8. https://doi.org/10.1200/op.20.00269.

110. Ippolito E, Fiore M, Greco C, D'Angelillo RM, Ramella S. COVID-19 and radiation induced pneumonitis: overlapping clinical features of different diseases. Radiother Oncol. 2020;148: 201-2. https://doi.org/10.1016/j.radonc.2020.04.009.

111. Torales J, O'Higgins M, Castaldelli-Maia JM, Ventriglio A. The outbreak of COVID-19 coronavirus and its impact on global mental health. Int J Soc Psychiatry. 2020;66(4):317-20. https://doi. org/10.1177/0020764020915212.

112. Chen-See S. Disruption of cancer care in Canada during COVID19. Lancet Oncol. 2020;21(8):e374. https://doi.org/10.1016/ s1470-2045(20)30397-1.

113. Shanafelt T, Ripp J, Trockel M. Understanding and addressing sources of anxiety among health care professionals during the COVID-19 pandemic. Jama. 2020. https://doi.org/10.1001/jama. 2020.5893 .

Publisher's Note Springer Nature remains neutral with regard to jurisdictional claims in published maps and institutional affiliations. 